\title{
Imagens perigosas: a possessão e a gênese do cinema de Jean Rouch*
}

\author{
Renato Sztutman \\ Doutorando em Antropologia Social pela \\ FFLCH/USP e co-editor da revista Sexta-Feira: \\ antropologia, artes e humanidades.
}

Artigo aceito para publicação em 03/10/05

\begin{abstract}
resumo Este artigo trata da gênese do cinema de Jean Rouch (1917-2004), dando foco ao filme Les maîtres fous, de 1954. Com este, Rouch realiza a transição do filme etnográfico em seus moldes "clássicos" para um questionamento mais sofisticado sobre a linguagem. Ao filmar um ritual de possessão na Costa do Ouro (hoje em dia, Gana), Rouch acaba por promover uma reflexão sobre a relação entre realidade e imaginário, que diz muito sobre outra relação, aquela que se dá entre a práxis cinematográfica e a análise antropológica.
\end{abstract}

palavras-chave Jean Rouch, filme etnográfico, ritual, possessão.

Ao imaginário se chega quando se derrapa. Jean Rouch

\section{Accra, Paris, 1954}

Paris. 1954. Sala de projeção do Museu do Homem. Jean Rouch exibe pela primeira vez o curta-metragem Les Maîtres Fous, hoje reconhecido como marco na história do filme documentário e etnográfico, o que se deve à utilização de uma nova linguagem cinematográfica para re-

* Uma primeira versão deste texto foi apresentado no 28a encontro anual da ANPOCS (outubro de 2004) na mesa "Jean Rouch, cinema, antropologia", realizada como uma homenagem a esse importante antropólogo e cineasta, falecido em fevereiro de 2004, aos 84 anos, num acidente de carro ocorrido no Níger. abstract This article lies on the genesis of Jean Rouch's cinema (1917-2004). Its focus is on the film Les maîtres fous, which first appeared in 1954. With this film, Rouch abandons ethnographic film in its "classical" fashion towards a more sophisticated investigation on language. While filming a possession ritual in the Golden Cost (nowadays, Ghana), Rouch finds a reflection on reality-imaginary relationship, which seems to be able to tell too much about the relationship between cinematographic praxis and anthropological analysis.

keywords Jean Rouch, ethnographic film, ritual, possession.

tratar um ritual africano de possessão, realizado num contexto colonial e urbano. Estão presentes na platéia africanistas como Marcel Griaule, Luc de Heusch e Germaine Dieterlen, além de alguns alunos, muitos deles de origem africana. As luzes se apagam. A cortina vermelha se abre. A projeção começa.

$\mathrm{Na}$ tela, a imagem estática de uma oferenda de comida. De fundo, a música africana mistura-se a ruídos urbanos. Um texto nos explica que o filme versará sobre um episódio da vida

Agradeço a Paulo Menezes, coordenador, pelo convite gentil e pela oportunidade que me propiciou de refletir, junto a pesquisadores da área de antropologia visual, sobre a obra de Rouch. Agradeço também a Sophie Abiven e Stelio Marras, que discutiram comigo algumas das questóes aqui expostas. 
dos Hauka, membros de uma certa "seita" religiosa que incorporam "novos deuses". O texto adverte ainda que as imagens fortes que seguirão foram filmadas a pedido dos sacerdotes e que nenhuma delas é proibida ou secreta, sendo assim abertas a todos que estiverem dispostos a assistir ao "jogo violento que nada mais é senão o reflexo de nossa civilização".

Um corte abrupto nos leva a uma estação de trem e, logo depois, ao cenário urbano. Rouch conta-nos, em voz off (como o fará ao longo de todo o filme), que estamos numa certa cidade da África Ocidental - Accra, capital da então Costa do Ouro, colônia britânica, hoje Gana. Vemos homens trabalhar - são todos migrantes que vêm de diferentes partes. Doqueiros, estivadores, comerciantes, artesãos, faxineiros, mineiros, entre tantos outros compóem essa "Babilônia Negra". A sobreposição de diferentes planos indica a convivência de sons, cores e religióes. Em um bar, denominado Califórnia, ouvimos o som do calipso. De um cortejo iorubá passamos a uma manifestação de prostitutas, destas às irmãzinhas de Jesus que "cantam nas ruas a sua fé" e, por fim, a uma fanfarra militar.

Chegamos ao mercado de sal, na periferia de Accra, onde se encontram os Hauka. Rouch explica que domingo é o dia em que eles se reúnem para celebrar os "novos deuses" e, nesse momento, oferece flashes de rostos em transe, antecipando a matéria do filme. São rostos desfigurados que se confundem na escuridão. $\mathrm{Na}$ seqüência seguinte, já é domingo. Logo cedo, os Hauka deixam a cidade em direção ao sítio, onde será realizado o ritual. Quem guia todos é Mountyeba, o "sacerdote" que, como os demais, é um migrante vindo do Níger.

No sítio, o velho casebre é apresentado como "palácio do governador" e lá encontramos um altar com o ícone do governador britânico. $\mathrm{O}$ ritual começa entáo com a apresentação de um noviço, Gherba, que tem crises intensas em frente à câmera - todos sabem que ele está possuído por um espírito Hauka. Em seguida, têm início as confissóes públicas. Um homem diz que teve relaçóes sexuais com a esposa do amigo e há dois meses está impotente. Outro diz que colocou em dúvida a existência dos espíritos Hauka. Um apito dá o sinal de ordem e os punidos separamse dos demais, ficando de fora do pátio, vigiado por sentinelas. Uma galinha é sacrificada e seu sangue é esparramado no altar.

Sobre a estátua do governador, vemos uma mensagem telegráfica e um cartaz do filme "A marca do Zorro". Já passa das dez da manhã e um violinista começa a tocar as árias Hauka. $\mathrm{O}$ sacerdote dorme. Alguém traz um cão, que deverá ser sacrificado e comido. Rouch explica que o sentido deste ato está em romper um tabu, o que os permite mostrar - para os africanos e para os europeus - que eles são mais fortes que os outros homens. Todos se póem a marchar em torno do local onde será realizado o sacrifício - eles portam faixas vermelhas e fuzis de madeira. Seu comportamento imita a disciplina militar européia. A dança principia, puxada pelo sacerdote. A câmera procura acompanhar o movimento efusivo dos participantes. De repente, a possessão começa. Acompanhamos de perto as reaçóes corporais de um homem. A tremedeira se inicia pelo pé esquerdo, passa ao direito, invadindo as mãos, os braços, os ombros e, por fim, a cabeça. Esse homem, reconhecido como cabo de guarda, levanta-se, cumprimenta a todos e pede fogo para se queimar - ele precisa mostrar que “já não é um homem, mas um Hauka”, comenta Rouch.

Aos poucos, todo o panteão de oficiais militares desce ao pátio. Vêm o capitáo, o condutor da locomotiva, Madame Locotereau, o tenente, o governador e Madame Salme. A câmera, fortemente subjetiva, busca acompanhar os movimentos aparentemente desgovernados dos personagens em transe, alternando entre planos de conjunto, que focalizam a dança e a algazarra, e closes em diferentes expressóes faciais, temperadas pela baba branca que escorre das bocas. 
De súbito, o tenente aproxima-se da estátua do governador e, como num ato sacrificial, quebra sobre ela um ovo de galinha. No plano seguinte, vamos parar no desfile do exército britânico com suas cores gritantes. Rouch explica que a função simbólica do ovo pode ser buscada naquelas imagens e, no plano seguinte, focaliza as penas amarelas e brancas do capacete do governador em carne e osso. $\mathrm{O}$ que víamos como imitação agora é realidade: os militares, de uniforme vermelho, realizam uma parada em frente à Assembléia de Accra. Há um público imenso que assiste ao espetáculo e, lembra-nos Rouch, haverá ali certamente um Hauka que veio buscar seu modelo.

Um novo corte nos devolve ao ritual. A possessão continua. $\mathrm{O}$ governador convoca uma assembléia para decidir se o cão será comido cru ou cozido. Decide-se cozinhá-lo. (Enquanto isso, o noviço chega possuído pelo "secretário geral”). Morto, o cão é feito em pedaços, e os homens, inquietos, fartam-se com o seu sangue. Pronto o cozido, os melhores pedaços são disputados. As imagens são de causar náuseas. Com o cair da noite, o ritual termina a não ser para o motorista da locomotiva que se póe a discursar. Momentos depois, todos deixam o sítio. Por um instante, sob a escuridão, vemos os vestígios do rito.

$\mathrm{Na}$ manhã seguinte, Rouch nos traz de volta ao mercado de sal, onde reencontramos os personagens da véspera - todos sorridentes, sem qualquer aparência de ressaca. Vemos ali uma nova assembléia, não para decidir a morte de um cão, mas para jogar cartas. Rouch ajuda-nos a reconhecer os participantes, valendo-se de flashes dos rostos desfigurados da véspera. Madame Locotereau é, na verdade, um menino efeminado que trabalha como vendedor e usa muita vaselina no cabelo. O cabo de guarda é caminhoneiro. O general é só um soldado. Madame Salme é Magasia, uma prostituta. O governador, o condutor de locomotiva e o secretário geral são operários da Water Rocks, empresa de abastecimento de água. Por ironia, eles trabalham numa obra localizada em frente ao hospital psiquiátrico municipal. Jean Rouch fixa-se, entáo, no sorriso ingênuo de Gherba, o noviço que foi o secretário geral e agora tem a cabeça raspada. E, sobre essa imagem, o filme finda com uma indagação do próprio diretor: "Provavelmente, esses africanos conhecem certos remédios que os permitem não serem anormais, mas justamente se integrarem ao meio em que vivem. E estes remédios ainda nos são desconhecidos".

As luzes se acendem na sala de projeção do Museu do Homem. A platéia está atônita depois de assistir aos apenas vinte e sete minutos do filme. Alguns africanos presentes declaram que as imagens vistas são uma afronta à sua dignidade, que elas apresentam os nativos como selvagens. Marcel Griaule pede, então, que Rouch destrua o filme: aquelas imagens não poderiam ser veiculadas, visto que eram demasiadamente perigosas. Elas jamais poderiam ser vistas por não-iniciados, que não partilhassem aquele universo. Tampouco poderiam ser exibidas a iniciados, que, ao vê-las, entrariam em transe.

Uma história, contada por Rouch, é bastante curiosa para falar do perigo dos espíritos Hauka e de suas imagens:

Entre a minha equipe estava um jovem chamado Tallou que depois viria a atuar em Cocorico Monsieur Poulet (1975). Ele ficou chocado: “Tudo isso é falso. Falso!". E Gherba disse a ele: "Tallou, tome cuidado. Você não deveria dizer isso, pois os Hauka podem se vingar". Dito e feito. Três semanas depois, Tallou foi possuído. Foi um transe selvagem, que causou muito problema, pois ele foi possuído no meio de Accra e começou a agredir os seus amigos. Encontramos-no passando a noite num cemitério fora da cidade, e eu o levei a Mountyeba, o sacerdote, que disse: "Sim, ele está possuído, mas é preciso esperar quem sabe um ano para 
que ele seja finalmente iniciado". E disse também (mas só para mim): "Você é reponsável, pois foi você quem o trouxe aqui. $\mathrm{O}$ melhor a fazer é levá-lo de volta à sua aldeia natal". $\mathrm{O}$ sacerdote me deu um pouco de perfume e outras coisas mais e me explicou como aquietar Tallou se ele voltasse a ter uma crise. Entáo eu levei Tallou ao meu motorista, Lam, que, aliás, também atuou em meus filmes. Eles voltaram ao Níger de trem e caminhão, e durante a viagem ele foi possuído duas ou três vezes. Lam teve de o acalmar passando perfume em sua cabeça. Isso foi dois anos antes de sua iniciação. Um dos últimos Hauka foi um general francês que comandou o exército durante a guerra da Indochina. Ele se chamava General Marseilles, pois certas tropas africanas que partiam à Indochina paravam em Marselha, França. Tallou foi possuído por este general, o último dos Hauka (Rouch, Marshall \& Adams, 1978: 1010; minha tradução).

Durante o debate, Luc De Heusch é o único a defender o filme de Rouch, apontando ali um documento de grande importância para a antropologia.

\section{Antecedentes e ecos}

Para além do Museu do Homem, Les Maîtres Fous não teve melhor sorte. Foi rechaçado pelas autoridades coloniais britânicas, que acusaram o autor de desrespeito ao Exército e à rainha. Tendo em vista todas as objeçôes, Rouch optou por restringir a circulação do filme, exibindo-o apenas em um circuito alternativo de cineclubes.

Com todos esses pesares - e mesmo por causa deles - Les Maîtres Fous tornou-se um clássico. Inspirou rapidamente campos artísticos, como o cinema de ficção e o teatro. Claude Chabrol foi logo procurar Rouch para saber, afinal, como ele tinha adquirido tamanha técnica na direção de "atores". (O cineasta não havia acreditado que aquilo pudesse ser um ritual). Jean Genet, de sua parte, inspirou-se na possessáo Hauka para escrever Os Negros, peça em que um grupo de escravos se rebela contra seus mestres. E Peter Brook usou as imagens para treinar os atores de Marat/Sade.

De modo curioso, Les Maîtres Fous atraía, sobretudo, pelo seu lado dramático. Como filme etnográfico, no entanto, foi considerado, por pares como o próprio Griaule, como incompleto, por ser breve demais e não contextualizar na medida necessária o ritual apresentado, e perigoso, por náo medir o efeito que aquelas imagens poderiam ter para a audiência, africana e européia (Stoller 1994). Que seriam, afinal, aqueles homens negros ditos Hauka, que imitavam personagens coloniais e eram possuídos pelos seus espíritos? Que pensar de uma cena escatológica como a do sacrifício do cão, em que se cogitou a possibilidade de comer a carne crua? Acusava-se o filme de Jean Rouch de endossar justamente o que ele pretendia combater, ou seja, o racismo, a idéia de que a subordinação poderia ser explicada pelo caráter "selvagem" (portanto, "inferior") dos negros, que agiam na tela como doentes mentais, incapazes de separar a realidade vivida da imaginação.

Apesar da recepção receosa por parte dos antropólogos, Les Maîtres Fous não pode ser dissociado do processo de pesquisa iniciado por Rouch em meados dos anos 1940 no que viria a ser a República do Níger, e nesse ponto recobra um lugar importante na história da antropologia e do cinema. Rouch formou-se em engenharia civil e se tornou supervisor da construção de estradas na colônia francesa ali estabelecida. Foi nesse cenário que conheceu Damouré Zika, que se tornaria um grande amigo e parceiro. Damouré trabalhou como técnico de som em filmes como o próprio Les Maîtres Fous, e protagonizou outros filmes como Jaguar (1967) e Petit à Petit (1969). Também ali Rouch presenciou os primeiros rituais de possessão, que o conduziram a refletir 
mais sistematicamente sobre aspectos daquelas religióes e, assim, reavivar os estudos de etnologia realizados quando era ainda um aluno de graduação. Com apoio de Griaule, Rouch passou a se interessar pela coleta de dados e pela religiáo dos Songhay - povo agricultor da savana - antes da presença islâmica, o que incluía o interesse por práticas como feitiçaria, sacrifício e possessão. Rouch acompanhou, durante 1946 e 1947, uma expedição ao longo do rio Níger e filmou, entre outras coisas, uma caçada de hipopótamos. Como conta Paul Stoller (2005), foi devido a um tripé quebrado que Rouch teve de passar a usar a câmera na mão. Por acidente, ele cunhava um método muito particular de filmar. Essa seria a sua marca desde o primeiro filme, $A u$ pays des mages noirs (1947), exibido como complemento de Stromboli (1949), longa-metragem do diretor italiano Roberto Rosselini, que contava com a presença da atriz Ingrid Bergman no elenco.

Em 1947, já incluído no Centre National de la Recherche Scientifique (CNRS), Rouch partia como doutorando ao Níger e ao Mali para colher histórias sobre os Songhay do período pré-islâmico. Ele encontrava nos rituais realizados por esse povo a via de acesso mais eficaz para a revelação dessa memória coletiva. Em Les magiciens de Wanzerbé (1948), ele apresentava um retrato da vida social em uma aldeia songhay famosa pelos seus feiticeiros. Por meio de um longo plano-seqüência, documentava um ato por assim dizer exótico para o espectador ocidental: o feiticeiro-dançarino cuspia um objeto de metal que estaria alojado em seu estômago. Les Fils de l'eau, longa-metragem de 1953, reunia imagens, rodadas no Níger e no Mali, de diferentes momentos rituais, tais a circuncisão dos meninos songhay, a caça ao hipopótamo no rio Níger e um rito funerário dogon. Em 1952, Rouch defendia na Sorbonne a sua tese de doutorado, A religiáo e a magia entre os Songhay, sob orientação de Marcel Griaule. A partir do mesmo ano, iniciava uma nova pesquisa, já inseparável do cinema e desta vez não mais entre grupos "tribalizados", mas sobre os migrantes que vinham do Níger - sobretudo Songhay - à Costa do Ouro. Boa parte desses migrantes integrava as práticas Hauka, que não eram assim tão inovadoras como se pode pensar. Incorporava-se aos rituais de possessão tradicionais "novos deuses", justamente os espíritos de administradores coloniais. A "seita", como foi logo taxada pelo governo colonial francês, teria emergido por volta de 1927 , e seus membros teriam sido expulsos do Níger por atemorizar as autoridades públicas, o que evidencia o enorme impacto - sobretudo político - que tiveram.

\section{Os Hauka revisitados}

As imagens dos corpos possuídos por divindades coloniais pareciam sintetizar de modo notável a experiência de povos como os Songhay em cidades algo cosmopolitas como Accra. E, com efeito, elas atuaram na fundação do cinema de Jean Rouch. Mas, como atentava Griaule, estas eram imagens perigosas e descontextualizadas (Stoller 1994).

Três anos após o lançamento de Les Maîtres Fous, em 1957, a Costa do Ouro tornava-se independente. A partir de então, os Hauka que lá viviam retornavam ao interior do Níger, recuperando o estilo de vida aldeão. Seu panteão, que configurava uma espécie de prática "fora da lei”, era aos poucos assimilado pelos sacerdotes tradicionais. Intrigado pelas imagens de Rouch, Paul Stoller, antropólogo norte-americano, voltou aos Songhay do Níger na década de 1980, portanto no período pós-colonial. Ao contrário do que previu Rouch, Stoller (1989 e 1995) sustenta que a religiáo dos Hauka não cessou com o fim da colonização, mas transformou-se no tempo e acarretou diferentes arranjos políticos. Basta aqui salientar que, com a independência do Níger, muitos Hauka tornaram-se membros do Supremo Conselho Militar, um deles chegando 
a ser eleito como presidente da República. Notase também que, nesse novo período, os Hauka foram responsáveis pela legitimaçáo de vários atos de violência política. Segundo Stoller, que perseguiu as metamorfoses dos Hauka na segunda metade do século XX, esses rituais de possessão não eram simplesmente um modo para resistir à colonizaçáo, mas sobretudo para constituir uma memória do grupo e, assim, habitar o tempo atual. E isso só era possível mediante um trabalho de "inscrição no corpo". O autor lembra também que, entre os Songhay, esse tipo de memória "incorporada" (embodied) contrasta com dois outros: uma tradição escrita, herdada do Islá, e uma tradição oral-épica, concentrada na figura dos griots, contadores de histórias e guardióes da tradição oral.

Em linhas gerais, o argumento de Stoller reside na idéia de que os rituais de possessão Hauka imitam o homem branco e sua organização militar para domesticá-los, controlá-los. $\mathrm{Na}$ esteira de Michael Taussig (1993), Stoller (1995) pensa o "poder mimético" embutido nesses atos de incorporaçáo. Povos como os Songhay teriam, assim, nos rituais de possessão uma espécie de máquina de processamento dos episódios de contato com a alteridade, que remete tanto a tempos imemoriais - o tempo do mito - como a tempos datados - a conquista muçulmana, a incorporação de outros grupos étnicos etc. Podemos concluir, com Stoller e Taussig, que a possessão entre esses povos é um ato a um só tempo cognitivo, histórico e político, e isso significa que esta maneira de habitar no mundo - de existir - passa necessariamente pelo simbólico ou, para usar um termo bastante frisado por Rouch, pelo imaginário, pela imaginaçâo.

$\mathrm{O}$ fato de que os Hauka incorporavam elementos coloniais às suas práticas correntes para poder, enfim, domesticá-los ou controlá-los segundo seus próprios termos deve explicar, por exemplo, a permissão dos sacerdotes para filmar o ritual. Rouch lembra, aliás, que Les Maîtres
Fous foi realizado a pedido dos próprios Hauka. "Minha hipótese é que eles usariam a câmera no culto da mesma forma que usaram uma arma de madeira" (Rouch, Marshall \& Adams 1978: 1007). O ritual se apropria, assim, de mais um elemento ocidental, que não é, diga-se de passagem, um elemento qualquer, mas sim dotado de grande valor a um só tempo simbólico e tecnológico, dado pela capacidade de reproduzir imagens em movimento e veiculá-las a um grande público. O cinema era, na época em que Rouch filmava em Accra, um dos signos mais fortes da modernidade: apropriar-se dele era claramente um modo de exibir controle sobre a situação e, principalmente, de tornar visível uma situação que permanecia invisível. Máquina de sonhos, o cinema poderia materializar, como na possessão, aspectos invisíveis do cosmos, criando um novo contexto de interação. Como sugere Michael Taussig, que volta a Les Maîtres Fous:

O filme toma de empréstimo a prática mágica da mímese no próprio momento da filmagem. O primitivismo no modernismo permite-se florescer. Nesse mundo colonial onde a câmera encontra-se com esses possessos por divindades, podemos realmente apontar o renascimento ocidental da faculdade mimética por meio da maquinaria mimética da modernidade (1993: 242; minha tradução).

Se as imagens de Les Maîtres Fous eram, como acusou Griaule, perigosas, isso ocorria sobretudo porque elas eram capazes de amplificar de maneira descontrolada (e aberta a diferentes manipulaçóes) os cultos de possessão e, por isso mesmo, deveriam ser veiculadas com cautela. Elas eram poderosas (no sentido de Taussig) e poderiam ser usadas não apenas para fins racistas, por parte dos colonizadores, mas também pelos próprios sacerdotes Hauka, que desejavam cooptar novos adeptos, o que poderia promover um crescimento desmedido do movimento e causar grande represália por 
parte da administração colonial. De fato, como já salientado, Les Maîtres Fous teve circulação restrita durante a década de 1950, atendo-se a um público seleto de intelectuais. Quando da descolonização, no entanto, Rouch pôde voltar a algumas das aldeias songhay, no Níger, e ali exibir o filme. Nesse novo momento, os espíritos Hauka já estavam em grande parte incorporados às práticas tradicionais e ao panteáo de divindades, o que retirava de seus cultos o caráter propriamente contestatório.

O dinamismo das tradiçóes songhay, notado por Stoller, pode ser confirmado em um comentário de Rouch a Marshall \& Adams (1978) sobre a incorporação, na fase pós-colonial, de uma nova classe de divindades. No início dos anos 1970, quando os espíritos Hauka pareciam ter sido aceitos pela maioria dos sacerdotes songhay, apareciam os assim chamados espíritos Sasale, "subversivos", porém de modo distinto ao dos Hauka. Espíritos de cantores, prostitutas, playboys etc., os Sasale apoderavam-se dos corpos de meninas e meninos fazendo-os reproduzir gestos eróticos ou obscenos. Essa "nova religiaao" - se assim for possível chamar toda forma incorporação de novas divindades num panteão cuja marca é justamente essa abertura ao evento - foi, conta Rouch, revestida de um significado contestatório e novamente reprimida pelo governo da República do Níger.

Esta nova religião está começando do mesmo jeito: ele é absolutamente underground, pois o governo é contra o sexo. Eu comecei um filme sobre isso, mas eles me pediram para não mostrá-lo, pois (...) todas as danças falavam sobre sexo: "Olhem só o meu clitóris", "Ah, como são maravilhosos os seus testículos", e daí por diante. Era uma coisa de louco. Como vocês vêem, isso acontece a todo o momento. (...) As pessoas não conseguem explicar o que elas estão fazendo, elas só podem mostrar o que elas estão pensando, e isso significa que durante todos es- ses anos, dos anos 1920 à independência, elas estavam pensando no poder militar, administrativo e burocrático e, agora, elas começaram a pensar mais no sexo e na morte. Os Hauka introduziram a idéia de pessoas fora-da-lei, o sentido exato da palavra (é importante ter mitos de pessoas fora-da-lei). Mas agora que os Hauka estáo dentro da lei, tomaram o poder, pois eles são os filhos de Dongo, é preciso que tivessem aparecido os novos fora-da-lei, os Sasale. Mesmo na situação política atual, continua funcionando (1978: 1013; minha tradução).

Hoje, as imagens de Rouch, que, como os espíritos europeus (os Hauka), são parte constitutiva da memória coletiva local, podem ser exibidas em lugares públicos como o Centro Cultural do Níger, sem causar maiores desconcertos. Seu perigo foi, como se vê, domesticado e, assim, deslocado para outros domínios. Com efeito, passados cinqüenta anos, podemos voltar a essas imagens e medir seu impacto para a história do cinema e da antropologia.

\section{Imagens possessas}

Se as imagens de Les Maîtres Fous são mesmo perigosas, isso ocorre sobretudo porque elas parecem estabelecer com a possessão uma associação por contigüidade. As imagens ambíguas criadas no ritual Hauka - de colonizados que incorporam (espíritos de) colonizadores - não apenas mimetizam elementos ocidentais, como querem Taussig e Stoller, mas condensam e dão visibilidade às contradiçóes vividas na experiência cotidiana da época. ${ }^{1}$ Ora, o filme etnográfico inspira-se,

1. Carlo Severi (2000) vai além da idéia de mímese, presente em Stoller e Taussig, para pensar fenômenos "híbridos", tais os cultos Hauka, como resultado de um processo de interação ritual e de condensação de imagens. $\mathrm{O}$ ponto não seria apenas imitar os colonizadores, mas sobretudo inserir o seu universo, sobretudo imagético, dentro de um contexto ritual já dado; no caso Hauka, a possessão. 
curiosamente, nessa mesma relaçáo perigosa com o real. Filmar o ritual é, nesse sentido, menos retratá-lo que potencializá-lo, amplificá-lo. Eis que entra em cena o "cine-transe", expressão cunhada por Jean Rouch para se referir à filmagem de Les Maîtres Fous: é preciso filmar como se estivesse em transe para que o efeito do filme aproximese do efeito do ritual (Rouch 1978). De certo modo, se no ritual os africanos são cavalos de espíritos ocidentais, na sala de cinema a relação parece se inverter: tudo se passa como se nós nos tornássemos os cavalos deles.

A câmera do cineasta que participa ativamente da cena filmada possibilita para o público ocidental uma experiência análoga à do ritual africano. Les Maîtres Fous não é apenas perigoso para eles, mas também para nós, espectadores. Ainda que se trate de contextos radicalmente diversos, um mesmo tipo de impacto não pode ser negligenciado. É nessa mesma direção que Paul Stoller (1994) associa Les Maîtres Fous, e o cinema em geral criado por Rouch, às experiências dos surrealistas e, mais precisamente, ao "teatro da crueldade" de Antonin Artaud. O espectador é posto em confronto com dimensóes reprimidas - dando vazão ao inexprimível e ao invisível - e, assim, o filme pode transformar a audiência psicologicamente e politicamente, promovendo uma "descolonização do imaginário".

Como vemos, a missão do cinema confunde-se, em Jean Rouch, com a missão do ritual, no caso, de possessão. É assim que as filmagens da possessão Hauka encontram-se na base de seu "cinema verdade" - uma verdade que, no entanto, não diz respeito a um realismo ingênuo e que só pode ser revelada no discurso do cinema. Como Rouch assume inúmeras vezes, referindo-se sempre a Dziga Vertov, trata-se não de uma verdade nua, mas uma verdade fílmica, uma verdade do cinema. Náo de uma verdade visível, mas uma verdade que deve ser descortinada, inacessível ao olho senão pela mediação da câmera. A essa verdade se acede, vale ressaltar, pelo imaginário, pela imaginação.

Como o ritual, o cinema é uma espécie de explicitação de uma porção que permanece oculta e que só pode ser acionada na suspensão do cotidiano. ${ }^{2}$ A sala escura, como a possessão, permite que nos transportemos para outro mundo, o que significa voltar e ver este mundo já com outros olhos. Olhos de um recém-iniciado, tais aqueles que compóem a última seqüência de Les Maîtres Fous.

\section{Depois de Les Maîtres Fous}

O ritual de possessão Hauka e suas imagens perigosas podem ser tomados como fundadores do cinema rouchiano. É deles que emerge a potência provocadora e desafiadora dos filmes seguintes do realizador. Na segunda metade da década de 1950, as imagens aterrorizantes de Les Maîtres Fous davam lugar a outras formas de acessar o mundo por meio do imaginário e da imaginação, que passavam pela utilização da ficção e do psico-drama. O filme etnográfico sofria, então, uma reforma decisiva, visto que as fronteiras entre o ficcional e o documentário eram submetidas ao apuro.

Com Moi, un Noir (1958) e Jaguar (1967), duas "etno-ficcçôes", Rouch fazia os filmados encenarem as suas próprias vidas tendo como palco cidades assaltadas pela ocidentalização, como Abdijan (Costa do Marfim) e Accra (Gana). Esses filmes tratavam justamente dos sonhos de jovens africanos migrantes, que "espremidos entre a tradição e a automação, entre o islamismo e o álcool, não renunciaram às suas crenças nem aos ídolos modernos do boxe e do cinema" - tal o texto em off de Jean Rouch para a abertura de Moi, un Noir. Em La Pyramide Humaine (1959) e Chronique d'un Été (1960), Rouch lançava mão de

2. Sobre a idéia - que me é bastante simpática - de que objetivo da comunicação ritual é, sobretudo, tornar visível, "dar a ver" relaçôes invisíveis, ver Houseman \& Severi (1994). 
"psico-dramas sociais": reunia pessoas de diversas origens para discutir entre si e em frente à câmera, temas como racismo, xenofobia e guerra. A presença do realizador aí não era jamais transparente e os filmados falavam diretamente para a câmera. Em Pyramide Humaine, por exemplo, Rouch reunia estudantes brancos e negros que viviam em Abdijan para discutir com eles o tema das relaçóes raciais. Ao suscitar novos contextos de interaçáo entre os jovens, o filme acabava por produzir situaçóes, como o namoro entre um africano e uma francesa - situação que não era exatamente "pensável" naquela época tingida pelo colonialismo. Nesses filmes, vemos com mais nitidez também o projeto de uma "antropologia compartilhada" e o delineamento de um compromisso ético com os filmados. Ou seja, o filme etnográfico tornava-se um diálogo entre os nativos e o realizador, que deveria retornar a eles as imagens produzidas. ${ }^{3}$

Com esses filmes, Rouch rompe com a imposição de uma representação realista e com o ideal de transparência da câmera. Moi, un Noir busca na ficção o gênero ideal para se referir à experiência contraditória da modernidade e do cosmopolitismo vividos pelos migrantes africanos. Lembremos, contudo, que Les Maîtres Fous já antecipava esses aspectos, agarrando um tema clássico da antropologia: o ritual. Revelava como um certo grupo de homens e mulheres conseguia viver a colonização dentro de seus próprios termos; e estes, vale ressaltar, passavam pela possessão, pela inscrição no corpo de uma memória coletiva.

Se Les Maîtres Fous versa sobre a maneira pela qual o ritual pode trabalhar um impacto ou trauma causado pela colonizaçáo, ele resulta em imagens não menos impactantes e traumáticas para o espectador ocidental, impressionado com aqueles atos que evocam, no seu

3. Para uma discussão um pouco mais aprofundada sobre a porosidade das fronteiras entre o documentário e a ficção no cinema de Jean Rouch e a produção, por conseguinte, de uma "antropologia compartilhada", ver Sztutman (2004). imaginário, a loucura e a selvageria. Les Maîtres Fous foi, na época de seu lançamento, vítima de um mal-entendido, pois que a desordem que apresentava era, com efeito, um modo de estabelecer uma certa ordem, de conferir sentido a uma experiência marcada pela sobreposição de mundos distintos e distantes. Como já havia sugerido diversas vezes Claude Lévi-Strauss, que muitas vezes teorizou o que Rouch mostrou (mesmo que jamais tenha havido interlocução entre ambos), comparar as desordens psíquicas, como a concebemos no Ocidente, àquelas que parecem se apresentar, de maneira análoga, nas narrativas míticas e nos rituais de diversos povos ditos primitivos seria apenas possível e prudente se compreendêssemos que aqueles elementos de simbolização comumente tomados por nós como patologia - como expressóes do sofrimento individual - podem emergir, em outros lugares, como terapia - como modos de conferir sentido ou mesmo inibir o sofrimento a um só tempo individual e coletivo. ${ }^{4}$

A incorporação dos Hauka, uma espécie de materializaçáo das ambigüidades do cosmos e da sociedade, era a maneira específica pela qual os migrantes do Níger lidavam com o seu cotidiano,

4. Faço referência a textos como "A eficácia simbólica" (1976) e "Cosmopolitismo e esquizofrenia” (1986), nos quais Lévi-Strauss compara, respectivamente, os rituais xamânicos e a mitologia de dois grupos ameríndios - os Cuna da América Central e os Chinook da América do Norte - a domínios terapêuticos. Se a tendência foi comparar o xamã ao esquizofrênico e identificar nos motivos míticos elementos relacionados à esquizofrenia - tal o tema da clivagem interior e das confusóes exteriores -, Lévi-Strauss propóe uma inversão decisiva, comparando o trabalho do xamanismo e da mitologia ao trabalho do psiquiatra. O movimento por eles realizado seria, assim, inverso ao do delírio esquizofrênico, pois o que neste é interiorizado subjetivamente pelo doente, torna-se objetivamente espalhado entre diversos protagonistas e repartido por diversos aspectos do cosmos. "Os materiais simbólicos são talvez os mesmos, mas o mito e o delírio fazem deles usos opostos" (1986: 260). 
invadido pela experiência da ocidentalização. Era preciso dar aos colonizadores um lugar no panteáo de divindades para que, como as demais divindades, eles pudessem ser domesticados, submetidos ao jugo dos homens. Era preciso ser possuído por essas novas divindades, confundir-se com elas, condensar elementos nativos e estrangeiros, para que fosse possível voltar ao cotidiano não mais como sujeito cindido - aterrorizado pela tensão entre mundos descontínuos - mas como trabalhador que, integrado ao movimento caótico da cidade grande, jamais se esquece do compromisso sagrado no domingo. Em linhas gerais, a mensagem de Les Maîtres Fous consiste em dizer que para ser "normal", ou melhor, para suportar as contradiçóes do vivido e estabelecer um certo grau de autonomia pessoal, era preciso experimentar uma certa "loucura" e uma certa "selvageria", obtidas nessa entrega à imaginação, nessa interação com imagens e espíritos, que condensavam elementos da religião nativa e da situação colonial, criando novas formas e, através delas, novos sentidos para habitar o mundo.

Como o totemismo abordado por LéviStrauss (1961), toda essa "selvageria", que continua a chocar o olhar do espectador ocidental (que teme se descobrir selvagem), talvez não esteja longe de nós, mas sim em nós. O ponto é que ela é mobilizada de maneiras bastante opostas na experiência de cá e na de lá. Com suas imagens perigosas, que geram opinióes e efeitos adversos e que os nativos temem extrapolar o domínio da tela, Rouch pretendia, em Les Maîtres Fous, fazer o "mundo africano" - com seus símbolos, ritos e mitos - afetar a nossa própria realidade. O cinema rouchiano constrói-se, tal o argumento deste pequeno ensaio, sob o signo do ritual de possessão, que lhe oferece, sem abolir o perigo, um certo modo de mostrar e agir sobre o mundo, passando pela proposiçáo de um outro mundo, prenhe de imagens ambíguas, entre a humanidade e a divindade, entre o tradicional e o moderno.
Com Rouch, o cinema deixa de ser mera ilusão para se converter numa práxis capaz de descortinar uma "verdade muito particular", jamais dada na superfície visível das coisas, mas que deve ser extraída, ou mesmo decretada, sob esforço da imaginação. Tendo em vista esse notável projeto, Les Maîtres Fous, inquietante tanto pelo seu tema quanto pela sua linguagem, permanece eternizado no panteáo do cinema e da antropologia.

\section{Referências bibliográficas}

HOUSEMAN, Michael \& SEVERI, Carlo. 1994. Naven ou le donner à voir: essai d'interprétation de l'action rituelle. Paris: Eds. MSH/CNRS.

LÉVI-STRAUSS, Claude. 1961. Le totemisme aujourd'hui. Paris: PUF.

1976. "A eficácia simbólica" In Antropologia estrutural. Rio de Janeiro: Tempo Brasileiro, pp. 215-236. 1986. "Cosmopolitismo e esquizofrenia" In $O$ olhar distanciado. Lisboa: Ed. 70, pp. 253-164.

ROUCH, Jean. 1960. La religion et la magie Songhay. Paris: PUF.

1978. "On the vicissitudes of the self: the possessed dance, the magician, the sorcerer, the filmmaker and the ethnographer". Studies in the Anthropology of visual communication. 5 (1), pp. 112-121.

ROUCH, Jean, MARSHALL, John \& ADAMS, John. 1978. "Jean Rouch talks about his films to John Marshall and John W. Adams". American Anthropologist. 80 (4), pp. 1005-1022.

SEVERI, Carlo. 2000. "Cosmologia, crise e paradoxo: da imagem de homens e mulheres brancos na tradição xamânica cuna”. Mana. 6 (1), p. 121-155.

STOLLER, Paul. 2005. Ciné-trance: a tribute to Jean Rouch. In American Anthropologist. 107, p. 123-126.

1989. Fusion of the worlds: an ethnography of possession among the Songhay of Niger. Chicago: Chicago University Press.

1994. "Artaud, Rouch and the cinema of cruelty" In Taylor, Lucien (ed.). Visualizing theory: selected essays from V.A.R. London: Routledge, pp. 84-98.

1995. Embodying colonial memories: sprit possession, power and the Hauka in West Africa. New York: Routledge.

SZTUTMAN, Renato. 2004. "Jean Rouch, um antropólogo-cineasta”. In CAIUBY NOVAES, Sylvia et alli (orgs.) Escrituras da imagem. São Paulo: Edusp, pp. 49-62. 